\title{
Design Serial Fuzzy Variable Structure Compensator for Linear PD Controller: Applied to Rigid Robot
}

\author{
Farzin Piltan \\ Senior Researcher at Research and Development Unit, SanatkadeheSabze Pasargad company, (S.S.P. Co), Shiraz, Iran \\ E-mail:Piltan_f@iranssp.com
}

Saleh Mehrara

Research and Development Unit, SanatkadeheSabze Pasargad company, (S.S.P. Co), Shiraz, Iran E-mail:SSP.ROBOTIC@yahoo.com

Javad Meigolinedjad

Research and Development Unit, SanatkadeheSabze Pasargad company, (S.S.P. Co), Shiraz, Iran E-mail:SSP.ROBOTIC@yahoo.com

Reza Bayat

Research and Development Unit, SanatkadeheSabze Pasargad company, (S.S.P. Co), Shiraz, Iran E-mail:SSP.ROBOTIC@yahoo.com

\begin{abstract}
In this paper, a PD-serial fuzzy based robust nonlinear estimator for a robot manipulator is proposed by using robust factorization approach. That is, considering the uncertainties of dynamic model consisting of measurement error and disturbances, a PD with fuzzy estimator variable structure nonlinear feedback control scheme is designed to reduce effect of uncertainties. This research aims to design a new methodology to fix the position in robot manipulator. PD method is a linear methodology which can be used for highly nonlinear system's (e.g., robot manipulator). To estimate this method, new serial fuzzy variable structure method (PD.FVSM) is used. This estimator can estimate the parameters to have the best performance.
\end{abstract}

Index Terms - Robot Manipulator, Fuzzy Logic Methodology, Variable Structure Control, Linear PD Methodology, Estimator, Fuzzy Variable Structure Estimator

\section{Introduction}

Robot manipulator is a collection of links that connect to each other by joints, these joints can be revolute and prismatic that revolute joint has rotary motion around an axis and prismatic joint has linear motion around an axis. Each joint provides one or more degrees of freedom (DOF) [1-8]. From the mechanical point of view, robot manipulator is divided into two main groups, which called; serial robot links and parallel robot links. Most of industrial robots are serial links, which in $n$ degrees of freedom serial link robot manipulator the axis of the first three joints has a known as major axis, these axes show the position of endeffector, the axis number four to six are the minor axes that use to calculate the orientation of end-effector and the axis number seven to $n$ use to reach the avoid the difficult conditions (e.g., surgical robot and space robot manipulator). Kinematics is an important subject to find the relationship between rigid bodies (e.g., position and orientation) and end-effector in robot manipulator. The mentioned topic is very important to describe the three areas in robot manipulator: practical application such as trajectory planning, essential prerequisite for some dynamic description such as Newton's equation for motion of point mass, and control purposed therefore kinematics play important role to design accurate controller for robot manipulators. Robot manipulator kinematics is divided into two main groups: forward kinematics and inverse kinematics where forward kinematics is used to calculate the position and orientation of end-effector with given joint parameters (e.g., joint angles and joint displacement) and the activated position and orientation of end-effector calculate the joint variables in Inverse Kinematics[6-13] Dynamic modeling of robot manipulators is used to describe the behavior of robot manipulator such as linear or nonlinear dynamic behavior, design of model based controller such as pure variable structure controller and pure computed torque controller which design these controller are based on nonlinear dynamic 
equations, and for simulation. The dynamic modeling describes the relationship between joint motion, velocity, and accelerations to force/torque or current/voltage and also it can be used to describe the particular dynamic effects (e.g., inertia, coriolios, centrifugal, and the other parameters) to behavior of system[14-23].

The Controller is a device which can sense information from linear or nonlinear system (e.g., robot manipulator) to improve the systems performance [2433]. The main targets in designing control systems are stability, good disturbance rejection, and small tracking error[5]. Several industrial robot manipulators are controlled by linear methodologies (e.g., ProportionalDerivative (PD) controller, Proportional- Integral (PI) controller or Proportional- Integral-Derivative (PID) controller), but when robot manipulator works with various payloads and have uncertainty in dynamic models this technique has limitations. In some applications robot manipulators are used in an unknown and unstructured environment, therefore strong mathematical tools used in new control methodologies to design nonlinear robust controller with an acceptable performance (e.g., minimum error, good trajectory, disturbance rejection) [34-38]. To reduce the above challenges, the nonlinear robust controller is used to control of robot manipulator. Variable structure controller (VSC) is a powerful nonlinear robust controller under condition of partly uncertain dynamic parameters of system [39-45]. This controller is used to control of highly nonlinear systems especially for robot manipulators. Chattering phenomenon and nonlinear equivalent dynamic formulation in uncertain dynamic parameter are two main drawbacks in pure variable structure controller [46-53]. The chattering phenomenon problem in pure variable structure controller is reduced by using linear saturation boundary layer function or applied artificial intelligence in this controller. The nonlinear equivalent dynamic formulation problem in uncertain system is solved by using fuzzy logic theorem [8]. Fuzzy logic theory is used to remove or estimate the system's dynamics. To estimate the system dynamics, fuzzy logic methodology is applied to VSC to design an acceptable estimator.

Proposed MIMO linear PD controller with serial error-based fuzzy variable structure controller is a chattering free dynamic model-free controller compensator. This methodology is based on applied fuzzy logic in equivalent nonlinear dynamic part to estimate unknown parameters and applied this methodology to PD controller to estimate it. Linear PD controller has difficulty to control of nonlinear systems then VSC applied to PD controller to estimate it. Pure VSC has difficulty in handling unstructured model uncertainties, it is possible to solve this problem by combining fuzzy logic theory and VSC. This method is based on eliminate the equivalent part in fuzzy variable structure method (FVSC) to estimate the nonlinearity term in PD controller. The FVSC improve the variable structure surface gain $(\lambda)$ as well as improve the output performance by eliminate the equivalent part based on artificial intelligence rule. Error-based fuzzy serial VSC is stable model-free estimator for linear PD controller which does not need to limits the dynamic model of robot manipulator and eliminate the chattering phenomenon without to use the boundary layer saturation function.

This paper is organized as follows: In section 2, main subject of modeling robot manipulator formulation, linear PD controller, variable structure methodology and fuzzy logic method are presented. Detail of proposed methodology is presented in section 3. In section 4 , the simulation result is presented and finally in section 5 , the conclusion is presented.

\section{Theory}

\subsection{Robot Manipulator's Dynamic:}

Dynamic modeling of robot manipulators is used to describe the behavior of robot manipulator such as linear or nonlinear dynamic behavior, design of model based controller such as pure variable structure controller and pure computed torque controller which design these controller are based on nonlinear dynamic equations, and for simulation. The dynamic modeling describes the relationship between joint motion, velocity, and accelerations to force/torque or current/voltage and also it can be used to describe the particular dynamic effects (e.g., inertia, coriolios, centrifugal, and the other parameters) to behavior of system[1]. The Unimation PUMA 560 serially links robot manipulator was used as a basis, because this robot manipulator is widely used in industry and academic. It has a nonlinear and uncertain dynamic parameters serial link 6 degrees of freedom (DOF) robot manipulator. The equation of an $n-D O F$ robot manipulator governed by the following equation $[1,4$, 15-29, 41-53]:

$$
M(q) \ddot{q}+N(q, \dot{q})=\tau
$$

Where $\tau$ is actuation torque, M (q) is a symmetric and positive define inertia matrix, $N(q, \dot{q})$ is the vector of nonlinearity term. This robot manipulator dynamic equation can also be written in a following form [1-29]:

$$
\tau=M(q) \ddot{q}+B(q)[\dot{q} \dot{q}]+C(q)[\dot{q}]^{2}+G(q)
$$

Where $\mathrm{B}(\mathrm{q})$ is the matrix of coriolios torques, $\mathrm{C}(\mathrm{q})$ is the matrix of centrifugal torques, and $\mathrm{G}(\mathrm{q})$ is the vector of gravity force. The dynamic terms in equation (2) are only manipulator position. This is a decoupled system with simple second order linear differential dynamics. In other words, the component $\ddot{q}$ influences, with a double integrator relationship, only the joint variable $q_{i}$, independently of the motion of the other joints. 
Therefore, the angular acceleration is found as to be [3, 41-53]:

$$
\ddot{q}=M^{-1}(q) \cdot\{\tau-N(q, \dot{q})\}
$$

This technique is very attractive from a control point of view.

\subsection{Linear PD Main Controller}

Design of a linear methodology to control of robot manipulator was very straight forward. Since there was an output from the torque model, this means that there would be two inputs into the PD controller. Similarly, the outputs of the controller result from the two control inputs of the torque signal. In a typical PD method, the controller corrects the error between the desired input value and the measured value. Since the actual position is the measured signal. Figure 1 shows the linear PD methodology, applied to robot manipulator.

$$
\begin{aligned}
& e(t)=\theta_{\text {target }}(t)-\theta_{d}(t) \\
& U_{\alpha}=K_{p_{a}} e+K_{V_{a}} \dot{e}
\end{aligned}
$$

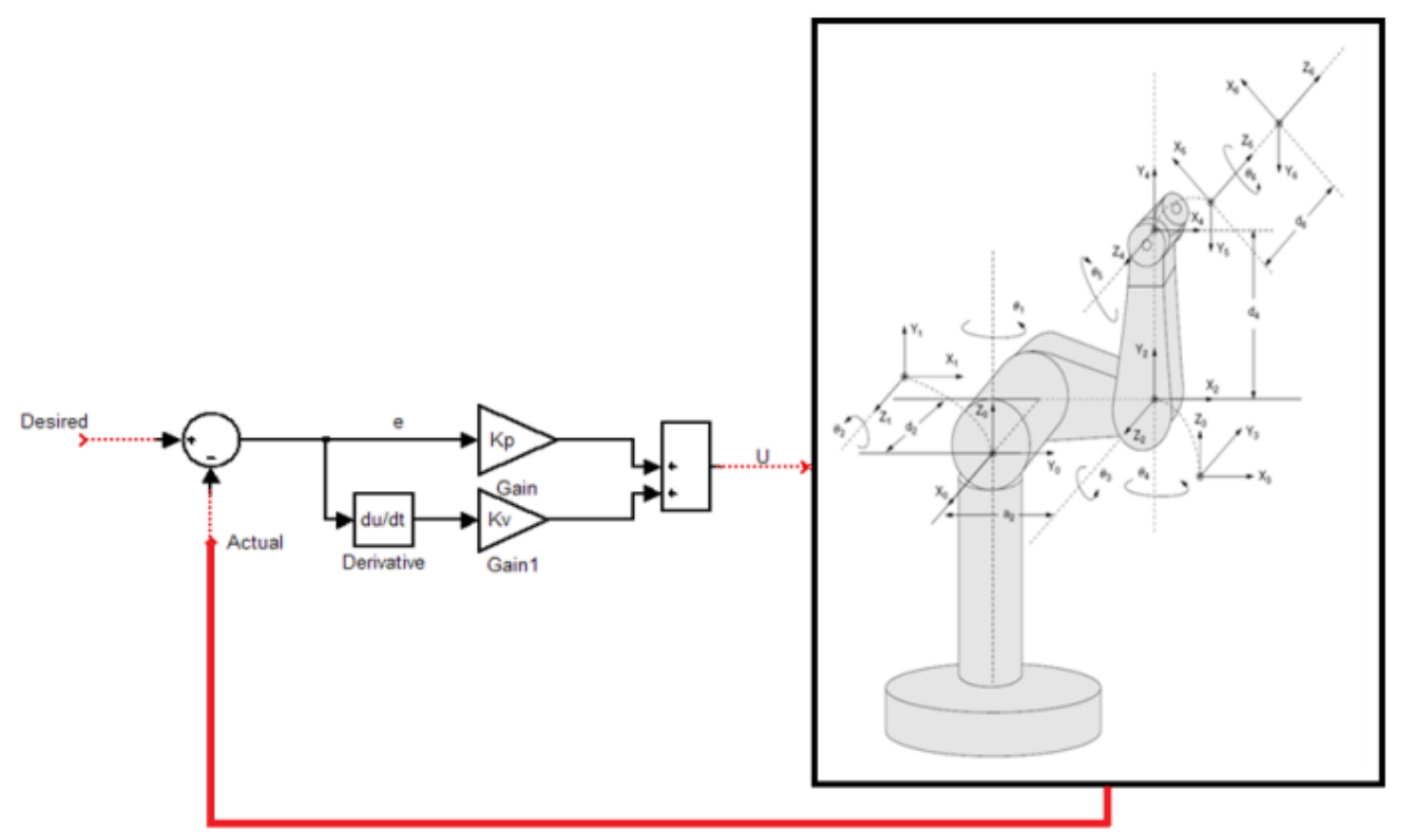

Fig. 1: Block diagram of linear PD method

The model-free control strategy is based on the assumption that the joints of the manipulators are all independent and the system can be decoupled into a group of single-axis control systems [18-23]. Therefore, the kinematic control method always results in a group of individual controllers, each for an active joint of the manipulator. With the independent joint assumption, no a priori knowledge of robot manipulator dynamics is needed in the kinematic controller design, so the complex computation of its dynamics can be avoided and the controller design can be greatly simplified. This is suitable for real-time control applications when powerful processors, which can execute complex algorithms rapidly, are not accessible. However, since joints coupling is neglected, control performance degrades as operating speed increases and a manipulator controlled in this way is only appropriate for relatively slow motion [44, 46]. The fast motion requirement results in even higher dynamic coupling between the various robot joints, which cannot be compensated for by a standard robot controller such as PD [50], and hence model-based control becomes the alternative.

\subsection{Variable Structure Controller}

Consider a nonlinear single input dynamic system is defined by [6]:

$$
x^{(n)}=f(\vec{x})+b(\vec{x}) u
$$

Where $\mathrm{u}$ is the vector of control input, $\boldsymbol{x}^{(\boldsymbol{n})}$ is the $\boldsymbol{n}^{\text {th }}$ derivation of $x, x=\left[x, \dot{x}, \ddot{x}, \ldots, x^{(n-1)}\right]^{T}$ is the state vector, $\boldsymbol{f}(\boldsymbol{x})$ is unknown or uncertainty, and $\boldsymbol{b}(\boldsymbol{x})$ is of known sign function. The main goal to design this controller is train to the desired state; $\boldsymbol{x}_{\boldsymbol{d}}=$ $\left[x_{d}, \dot{x}_{d}, \ddot{x}_{d}, \ldots, x_{d}^{(n-1)}\right]^{T}$, and trucking error vector is defined by [6]:

$$
\widetilde{x}=x-x_{d}=\left[\widetilde{x}, \ldots, \widetilde{x}^{(n-1)}\right]^{T}
$$

A time-varying sliding surface $\boldsymbol{s}(\boldsymbol{x}, \boldsymbol{t})$ in the state space $\boldsymbol{R}^{\boldsymbol{n}}$ is given by [6]:

$$
s(x, t)=\left(\frac{d}{d t}+\lambda\right)^{n-1} \widetilde{x}=0
$$


where $\lambda$ is the positive constant. To further penalize tracking error, integral part can be used in sliding surface part as follows [6]:

$$
s(x, t)=\left(\frac{d}{d t}+\lambda\right)^{n-1}\left(\int_{0}^{t} \widetilde{x} d t\right)=0
$$

The main target in this methodology is kept the sliding surface slope $\boldsymbol{s}(\boldsymbol{x}, \boldsymbol{t})$ near to the zero. Therefore, one of the common strategies is to find input $\boldsymbol{U}$ outside of $\boldsymbol{s}(\boldsymbol{x}, \boldsymbol{t})$ [6].

$$
\frac{1}{2} \frac{d}{d t} s^{2}(x, t) \leq-\zeta|s(x, t)|
$$

where $\zeta$ is positive constant.

$$
\text { If } \mathbf{S}(\mathbf{0})>\mathbf{0} \rightarrow \frac{\mathrm{d}}{\mathrm{dt}} \mathbf{S}(\mathbf{t}) \leq-\zeta
$$

To eliminate the derivative term, it is used an integral term from $\mathrm{t}=0$ to $\mathrm{t}=\boldsymbol{t}_{\text {reach }}$

$$
\int_{t=0}^{t=t_{\text {reach }}} \frac{d}{d t} S(t) \leq-\int_{t=0}^{t=t_{\text {reach }}} \eta \rightarrow S\left(t_{\text {reach }}\right)
$$

Where $t_{\text {reach }}$ is the time that trajectories reach to the sliding surface so, suppose $\mathrm{S}\left(t_{\text {reach }}=0\right)$ defined as;

$$
0-S(0) \leq-\eta\left(t_{\text {reach }}\right) \rightarrow t_{\text {reach }} \leq \frac{S(0)}{\zeta}
$$

and

$$
\text { if } \begin{aligned}
\boldsymbol{S}(\mathbf{0})<0 \rightarrow 0- & S(0) \leq-\eta\left(\boldsymbol{t}_{\text {reach }}\right) \\
& \rightarrow \boldsymbol{S}(\mathbf{0}) \leq-\zeta\left(\boldsymbol{t}_{\text {reach }}\right) \\
& \rightarrow \boldsymbol{t}_{\text {reach }} \leq \frac{|\boldsymbol{S}(\mathbf{0})|}{\boldsymbol{\eta}}
\end{aligned}
$$

Equation (14) guarantees time to reach the sliding surface is smaller than $\frac{|\boldsymbol{S}(\mathbf{0})|}{\zeta}$ since the trajectories are outside of $S(t)$.

$$
\text { if } S_{t_{\text {reach }}}=S(0) \rightarrow \operatorname{error}\left(x-x_{d}\right)=0
$$

suppose $\mathrm{S}$ is defined as

$$
\begin{aligned}
s(x, t)=\left(\frac{d}{d t}+\lambda\right) & \tilde{x} \\
& =\left(\dot{\mathbf{x}}-\dot{\mathbf{x}}_{\mathbf{d}}\right)+\lambda\left(\mathbf{x}-\mathbf{x}_{\mathrm{d}}\right)
\end{aligned}
$$

The derivation of $\mathrm{S}$, namely, $\dot{S}$ can be calculated as the following;

$$
\dot{S}=\left(\ddot{\mathbf{x}}-\ddot{\mathbf{x}}_{\mathbf{d}}\right)+\lambda\left(\dot{\mathbf{x}}-\dot{\mathbf{x}}_{\mathbf{d}}\right)
$$

suppose the second order system is defined as;

$$
\ddot{\boldsymbol{x}}=\boldsymbol{f}+\boldsymbol{u} \rightarrow \dot{\boldsymbol{S}}=\boldsymbol{f}+\boldsymbol{U}-\ddot{\boldsymbol{x}}_{\boldsymbol{d}}+\lambda\left(\dot{\mathbf{x}}-\dot{\mathbf{x}}_{\mathrm{d}}\right)
$$

Where $\boldsymbol{f}$ is the dynamic uncertain, and also since $S=0$ and $\dot{S}=0$, to have the best approximation , $\widehat{\boldsymbol{U}}$ is defined as

$$
\widehat{U}=-\widehat{f}+\ddot{x}_{d}-\lambda\left(\dot{\mathbf{x}}-\dot{\mathbf{x}}_{\mathbf{d}}\right)
$$

A simple solution to get the sliding condition when the dynamic parameters have uncertainty is the switching control law [52-53]:

$$
U_{d i s}=\widehat{U}-K(\vec{x}, t) \cdot \operatorname{sgn}(s)
$$

where the switching function $\mathbf{s g n}(\mathbf{S})$ is defined as $[1,6]$

$$
\operatorname{sgn}(s)= \begin{cases}1 & s>0 \\ -1 & s<0 \\ 0 & s=0\end{cases}
$$

and the $\boldsymbol{K}(\overrightarrow{\boldsymbol{x}}, \boldsymbol{t})$ is the positive constant. Suppose by (10) the following equation can be written as,

$$
\begin{aligned}
\frac{1}{2} \frac{d}{d t} s^{2}(x, t)=\dot{S} \cdot S & =[f-\hat{f}-K \operatorname{sgn}(s)] \cdot S \\
= & (f-\hat{f}) \cdot S-K|S|
\end{aligned}
$$

and if the equation (14) instead of (13) the sliding surface can be calculated as

$$
\begin{aligned}
s(x, t)=\left(\frac{d}{d t}+\lambda\right)^{2} & \left(\int_{0}^{t} \widetilde{x} d t\right) \\
& =\left(\dot{\mathrm{x}}-\dot{\mathrm{x}}_{\mathrm{d}}\right)+2 \lambda\left(\dot{\mathrm{x}}-\dot{\mathrm{x}}_{\mathrm{d}}\right) \\
& -\lambda^{2}\left(\mathrm{x}-\mathrm{x}_{\mathrm{d}}\right)
\end{aligned}
$$

in this method the approximation of $\boldsymbol{U}$ is computed as [6]

$$
\widehat{U}=-\widehat{f}+\ddot{x}_{d}-2 \lambda\left(\dot{x}-\dot{x}_{d}\right)+\lambda^{2}\left(x-x_{d}\right)
$$

Based on above discussion, the variable structure control law for a multi degrees of freedom robot manipulator is written as $[1,6]$ :

$$
\tau=\tau_{e q}+\tau_{d i s}
$$

Where, the model-based component $\boldsymbol{\tau}_{\boldsymbol{e q}}$ is the nominal dynamics of systems calculated as follows [1]:

$$
\tau_{e q}=\left[M^{-1}(B+C+G)+\dot{S}\right] M
$$

and $\boldsymbol{\tau}_{\text {dis }}$ is computed as [1];

$$
\tau_{d i s}=K \cdot \operatorname{sgn}(S)
$$

By (27) and (26) the variable structure control of robot manipulator is calculated as;

$$
\tau=\left[M^{-1}(B+C+G)+\dot{S}\right] M+K \cdot \operatorname{sgn}(S)
$$


where $S=\lambda e+\dot{e}$ in PD-SMC and $S=\lambda e+\dot{e}+$ $\left(\frac{\lambda}{2}\right)^{2} \sum e$ in PID-SMC.

\subsection{Proof of Stability}

The lyapunov formulation can be written as follows,

$$
V=\frac{1}{2} S^{T} \cdot M \cdot S
$$

The derivation of $V$ can be determined as,

$$
\dot{V}=\frac{1}{2} S^{T} \cdot \dot{M} \cdot S+S^{T} M \dot{S}
$$

The dynamic equation of robot manipulator can be written based on the sliding surface as

$$
M \dot{S}=-V S+M \dot{S}+B+C+G
$$

It is assumed that

$$
S^{T}(\dot{M}-2 B+C+G) S=0
$$

by substituting (31) in (30)

$$
\begin{array}{r}
\dot{V}=\frac{1}{2} S^{T} \dot{M} S-S^{T} B+C S+S^{T}(M \dot{S}+B+C S+G) \\
=S^{T}(M \dot{S}+B+C S+G)
\end{array}
$$

suppose the control input is written as follows

$$
\begin{aligned}
\widehat{U}=\widehat{U_{\text {Nonlinear }}+\widehat{U_{d l s}}} & \\
& =\left[\widehat{M^{-1}}(B+C+G)+\dot{S}\right] \widehat{M} \\
& +K \cdot \operatorname{sgn}(S)+B+C S+G
\end{aligned}
$$

by replacing the equation (34) in (29)

$$
\begin{aligned}
\dot{V}=S^{T}(M \dot{S}+B+C & +G-\widehat{M} \dot{S}-\widehat{B+C} S+G \\
& -K \operatorname{sgn}(S) \\
& =S^{T}(\widetilde{M} \dot{S}+\widehat{B+C S}+G \\
& -K \operatorname{sgn}(S))
\end{aligned}
$$

and

$$
|\widetilde{M} \dot{S}+\widetilde{B+C S}+G| \leq|\widetilde{M} \dot{S}|+|\widetilde{B+C S}+G|
$$

The Lemma equation in robot arm system can be written as follows

$$
K_{u}=[|\widetilde{M} \dot{S}|+|B+C S+G|+\eta]_{i}, i=1,2,3,4, \ldots
$$

and finally;

$$
\dot{V} \leq-\sum_{i=1}^{n} \eta_{i}\left|S_{i}\right|
$$

\subsection{Fuzzy Logic Methodology}

Based on foundation of fuzzy logic methodology; fuzzy logic controller has played important rule to design nonlinear controller for nonlinear and uncertain systems [53]. However the application area for fuzzy control is really wide, the basic form for all command types of controllers consists of;

Input fuzzification (binary-to-fuzzy $[\mathrm{B} / \mathrm{F}]$ conversion) Fuzzy rule base (knowledge base), Inference engine and Output defuzzification (fuzzy-to-binary [F/B] conversion). Figure 2 shows the fuzzy controller part.

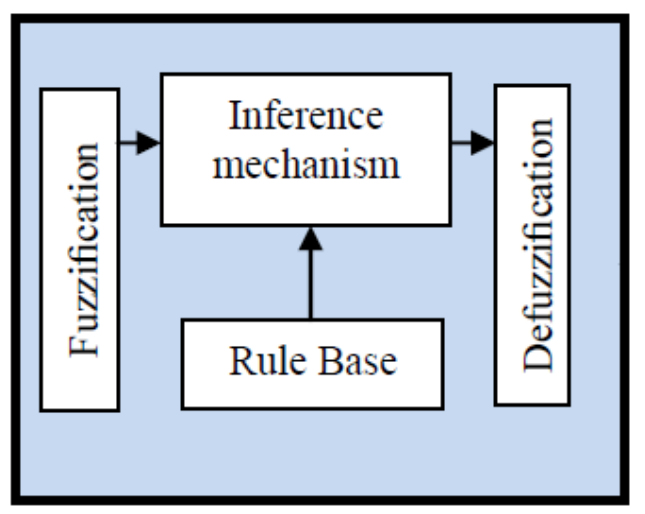

Fig. 2: Fuzzy Controller Part

The fuzzy inference engine offers a mechanism for transferring the rule base in fuzzy set which it is divided into two most important methods, namely, Mamdani method and Sugeno method. Mamdani method is one of the common fuzzy inference systems and he designed one of the first fuzzy controllers to control of system engine. Mamdani's fuzzy inference system is divided into four major steps: fuzzification, rule evaluation, aggregation of the rule outputs and defuzzification. Michio Sugeno use a singleton as a membership function of the rule consequent part. The following definition shows the Mamdani and Sugeno fuzzy rule base [22-33]

\section{if $x$ is $A$ and $y$ is $B$ then $z$ is $C$ 'mamdani' if $x$ is $A$ and $y$ is $B$ then $z$ is $f(x, y)$ 'sugeno'}

When $x$ and $y$ have crisp values fuzzification calculates the membership degrees for antecedent part. Rule evaluation focuses on fuzzy operation $(A N D / O R)$ in the antecedent of the fuzzy rules. The aggregation is used to calculate the output fuzzy set and several methodologies can be used in fuzzy logic controller aggregation, namely, Max-Min aggregation, Sum-Min aggregation, Max-bounded product, Max-drastic product, Max-bounded sum, Max-algebraic sum and Min-max. Defuzzification is the last step in the fuzzy inference system which it is used to transform fuzzy set to crisp set. Consequently defuzzification's input is the aggregate output and the defuzzification's output is a crisp number. Centre of gravity method (COG) and 
Centre of area method $(C O A)$ are two most common defuzzification methods.

\section{Methodology}

Based on the dynamic formulation of robot manipulator, (3), and the industrial PD law (5) in this paper we discuss about regulation problem, the desired position is constant, i.e., $\dot{q}_{d}=0$. In most robot manipulator control, desired joint positions are generated by the trajectory planning. The objective of robot control is to design the input torque in (1) such that the tracking error

$$
e=q_{d}-q_{a}
$$

When the dynamic parameters of robot formulation known, the PD control formulation (11) should include a compensator as

$$
\tau=-k_{p} e-k_{d} e+(G+F)
$$

Where $G$ is gravity and $F$ is appositive definite diagonal matrix friction term (coulomb friction). If we use a Lyapunov function candidate as

$$
\begin{aligned}
& V_{p d}=\frac{1}{2} \dot{q}^{T} M \dot{q}+\frac{1}{2} e^{T} k_{p} e \\
& \dot{V}_{p d}=-\dot{q}^{T} k_{d} \dot{q} \leq 0
\end{aligned}
$$

It is easy to known $\dot{q}=0$ and $e=0$ are only initial conditions in $\Omega=\{[\dot{q}, e]: \dot{V}=0\}$, for which $[\dot{q}, e] \in \Omega$ for al $1 t \leq 0$. By the LaSalle s invariance principle, $e \rightarrow 0$ and $\dot{e} \rightarrow 0$. When $\mathrm{G}$ and $\mathrm{F}$ in (11) are unknown, a fuzzy logic can be used to approximate them as

$$
f(x)=\sum_{l=1}^{M} \theta^{l} \mathcal{E}^{l}(x)=\theta^{T} \mathcal{E}(x)
$$

Where

$$
\theta=\left(\theta^{1}, \ldots, \theta^{M}\right)^{T}, \mathcal{E}(x)=
$$$$
\left(\mathcal{E}^{1}(x), \ldots, \mathcal{E}^{M}(x)\right)^{T} \text {, and } \mathcal{E}^{l}(x)=
$$

$: \prod_{i=1}^{n} \frac{\mu_{A_{i}^{l}}\left(x_{i}\right)}{} \sum_{l=1}^{M}\left(\prod_{i=1}^{n} \mu_{A_{i}^{l}}\left(x_{i}\right)\right) . \quad \theta^{1}, \ldots, \theta^{M} \quad$ are adjustable parameters in (44). $\mu_{A_{1}^{1}}\left(x_{1}\right), \ldots, \mu_{A_{n}^{m}}\left(x_{n}\right)$ are given membership functions whose parameters will not change over time.

The second type of fuzzy systems is given by

$$
f(x)=\frac{\sum_{l=1}^{M} \theta^{l}\left[\prod_{i=1}^{n} \exp \left(-\left(\frac{x_{i}-\alpha_{i}^{l}}{\delta_{i}^{l}}\right)^{2}\right)\right]}{\sum_{l=1}^{M}\left[\prod_{i=1}^{n} \exp \left(-\left(\frac{x_{i}-\alpha_{i}^{l}}{\delta_{i}^{l}}\right)^{2}\right)\right]}
$$

Where $\theta^{l}, \alpha_{i}^{l}$ and $\delta_{i}^{l}$ are all adjustable parameters. From the universal approximation theorem, we know that we can find a fuzzy system to estimate any continuous function. For the first type of fuzzy systems, we can only adjust $\theta^{l}$ in (45). We define $f^{\wedge}(x \mid \theta)$ as the approximator of the real function $f(x)$.

$$
f^{\wedge}(x \mid \theta)=\theta^{T} \varepsilon(x)
$$

We define $\theta^{*}$ as the values for the minimum error:

$$
\theta^{*}=\arg \min _{\theta \in \Omega}\left[\sup _{x \in U}\left|f^{\wedge}(x \mid \theta)-g(x)\right|\right]
$$

Where $\Omega$ is a constraint set for $\theta$. For specific $x, \sup _{x \in U}\left|f^{\wedge}\left(x \mid \theta^{*}\right)-f(x)\right|$ is the minimum approximation error we can get.

We used the first type of fuzzy systems (44) to estimate the nonlinear system (12) the fuzzy formulation can be write as below;

$$
\begin{aligned}
f(x \mid \theta) & =\theta^{T} \varepsilon(x) \\
& =\frac{\sum_{l=1}^{n} \theta^{l}\left[\mu_{A^{l}}(x)\right]}{\sum_{l=1}^{n}\left[\mu_{A^{l}}(x)\right]}
\end{aligned}
$$

Where $\theta^{1}, \ldots, \theta^{n}$ are adjusted by an adaptation law. The adaptation law is designed to minimize the parameter errors of $\theta-\theta^{*}$. The SISO fuzzy system is define as

$$
f(x)=\ominus^{T} \varepsilon(x)
$$

Where

$$
\ominus^{T}=\left(\theta_{1}, \ldots, \theta_{m}\right)^{T}=\left[\begin{array}{c}
\theta_{1}^{1}, \theta_{1}^{2}, \ldots, \theta_{1}^{M} \\
\theta_{2}^{1}, \theta_{2}^{2}, \ldots, \theta_{2}^{M} \\
\vdots \\
\theta_{m}^{1}, \theta_{m}^{2}, \ldots, \theta_{m}^{M}
\end{array}\right]
$$

$$
\varepsilon(x)=\left(\varepsilon^{1}(x), \ldots, \varepsilon^{M}(x)\right)^{T}, \quad \varepsilon^{1}(x)=\prod_{i=1}^{n} \mu_{A_{i}^{l}}\left(x_{i}\right) /
$$
$\sum_{l=1}^{M}\left(\prod_{i=1}^{n} \mu_{A_{i}^{l}}\left(x_{i}\right)\right)$, and $\mu_{A_{i}^{l}}\left(x_{i}\right)$ is defined in (48). To reduce the number of fuzzy rules, we divide the fuzzy system in to three parts:

$$
\begin{aligned}
& F^{1}(q, \dot{q})=\ominus^{1^{T}} \varepsilon(q, \dot{q}) \\
& =\left[\theta_{1}^{1^{T}} \varepsilon(q, \dot{q}), \ldots, \theta_{m}^{1^{T}} \varepsilon(q, \dot{q})\right]^{T} \\
& F^{2}\left(q, \ddot{q}_{r}\right)=\ominus^{2^{T}} \varepsilon\left(q, \ddot{q}_{r}\right) \\
& =\left[\theta_{1}^{2^{T}} \varepsilon\left(q, \ddot{q}_{r}\right), \ldots, \theta_{m}^{2^{T}} \varepsilon\left(q, \ddot{q}_{r}\right)\right]^{T} \\
& F^{3}(q, \ddot{q})=\ominus^{3^{T}} \varepsilon(q, \ddot{q}) \\
& =\left[\theta_{1}^{3^{T}} \varepsilon(q, \dot{q}), \ldots, \theta_{m}^{3^{T}} \varepsilon(q, \ddot{q})\right]^{T}
\end{aligned}
$$


The control security input is given by

$$
\begin{aligned}
& \tau=M \ddot{q}_{r}+B(q) \dot{q} \dot{q}+C(q) \dot{q}^{2}+ \\
& g(q)+F^{1}(q, \dot{q})+F^{2}\left(q, \ddot{q}_{r}\right)+F^{3}(q, \ddot{q})- \\
& K_{p} e-K_{v} \dot{e}
\end{aligned}
$$

Where $M^{\wedge}, \quad \boldsymbol{B}(\boldsymbol{q}) \dot{\boldsymbol{q}} \dot{\boldsymbol{q}}, \boldsymbol{C}(\boldsymbol{q}) \dot{\boldsymbol{q}}^{2}, \boldsymbol{g}(\boldsymbol{q})$ are the estimations of $M(q)$.

Based on sliding mode formulation (28) and PD linear methodology (5);

$$
S_{N e w}=(\dot{e}+\lambda e)
$$

And $U_{\text {switch }}$ is obtained by

$$
\begin{aligned}
& \mathrm{U}_{\text {switch }}=\mathrm{K}(\overrightarrow{\mathrm{x}}, \mathrm{t}) \cdot \operatorname{sgn}\left(\mathrm{S}_{\mathrm{New}}\right)=\mathrm{K}(\overrightarrow{\mathrm{x}}, \mathrm{t}) \cdot \\
& \operatorname{sgn}(K(\dot{e}+\lambda e))
\end{aligned}
$$

The Lyapunov function in this design is defined as

$$
V=\frac{1}{2} S^{T} M S+\frac{1}{2} \sum_{J=1}^{M} \frac{1}{\gamma_{s j}} \phi^{T} \cdot \phi_{j}
$$

where $\gamma_{s j}$ is a positive coefficient, $\boldsymbol{\phi}=\boldsymbol{\theta}^{*}-\boldsymbol{\theta}, \boldsymbol{\theta}^{*}$ is minimum error and $\theta$ is adjustable parameter. Since $\dot{M}-2 V$ is skew-symetric matrix;

$$
S^{T} M \dot{S}+\frac{1}{2} S^{T} \dot{M} S=S^{T}(M \dot{S}+V S)
$$

If the dynamic formulation of robot manipulator defined by

$$
\tau=M(q) \ddot{q}+V(q, \dot{q}) \dot{q}+G(q)
$$

The controller formulation is defined by

$$
\tau=\widehat{M} \ddot{q}_{r}+\hat{V} \dot{q}_{r}+\widehat{G}-\lambda S-K
$$

According to (58) and (59)

$$
\begin{aligned}
& M(q) \ddot{q}+V(q, \dot{q}) \dot{q}+G(q)=\widehat{M} \ddot{q}_{r}+\hat{V} \dot{q}_{r}+ \\
& \hat{G}-\lambda S-K
\end{aligned}
$$

Since $\dot{\boldsymbol{q}}_{r}=\dot{\boldsymbol{q}}-\boldsymbol{S}$ and $\ddot{\boldsymbol{q}}_{r}=\ddot{\boldsymbol{q}}-\dot{\boldsymbol{S}}$

$$
M \dot{S}+(V+\lambda) S=\Delta f-K
$$

$\boldsymbol{M} \dot{S}=\Delta f-K-V S-\lambda S$

The derivation of $\mathrm{V}$ is defined

$$
\dot{V}=S^{T} M \dot{S}+\frac{1}{2} S^{T} \dot{M} S+\sum_{J=1}^{M} \frac{1}{\gamma_{s j}} \phi^{T} \cdot \dot{\phi}_{j}
$$

$$
\dot{V}=S^{T}(M \dot{S}+V S)+\sum_{J=1}^{M} \frac{1}{\gamma_{s j}} \phi^{T} \cdot \dot{\phi}_{j}
$$

Based on (61) and (62)

$$
\begin{aligned}
& \dot{\mathrm{V}}=\mathrm{S}^{\mathrm{T}}(\Delta \mathrm{f}-\mathrm{K}-\mathrm{VS}-\lambda \mathrm{S}+\mathrm{VS})+ \\
& \sum_{\mathrm{J}=1}^{\mathrm{M}} \frac{1}{\gamma_{\mathrm{sj}}} \square^{\mathrm{T}} \cdot \dot{\square}_{\mathrm{j}}
\end{aligned}
$$

where

$\sum_{l=1}^{M} \theta^{T} \zeta(x)$

$$
\Delta f=[M(q) \ddot{q}+V(q, \dot{q}) \dot{q}+G(q)]-
$$

$$
\dot{V}=\sum_{J=1}^{M}\left[S_{j}\left(\Delta f_{j}-K_{j}\right)\right]-S^{T} \lambda S+\sum_{J=1}^{M} \frac{1}{\gamma_{s j}} \phi^{T} \cdot \dot{\phi}_{j}
$$

Suppose $K_{j}$ is defined as follows

$$
K_{j}=\frac{\sum_{l=1}^{M} \theta_{j}^{l}\left[\mu_{A}\left(S_{j}\right)\right]}{\sum_{l=1}^{M}\left[\mu_{A}\left(S_{j}\right)\right]}=\theta_{j}^{T} \zeta_{j}\left(S_{j}\right)
$$

Where $\zeta_{j}\left(S_{j}\right)=\left[\zeta_{j}^{1}\left(S_{j}\right), \zeta_{j}^{2}\left(S_{j}\right), \zeta_{j}^{3}\left(S_{j}\right), \ldots, \zeta_{j}^{M}\left(S_{j}\right)\right]^{T}$

$$
\zeta_{j}^{1}\left(S_{j}\right)=\frac{\mu_{(A)_{j}^{l}}^{l}\left(S_{j}\right)}{\sum_{i} \mu_{(A)}^{l}\left(S_{j}\right)}
$$

where $\mu_{(x i)}$ is membership function. The fuzzy system is defined as

$$
f(x)=\tau_{f u z z y}=\sum_{l=1}^{M} \theta^{T} \zeta(x)=\psi(e, \dot{e})
$$

where $\theta=\left(\theta^{1}, \theta^{2}, \theta^{3}, \ldots \ldots, \theta^{M}\right) \quad$ is adjustable parameter in (65)

According to (62), (63) and (65);

$$
\begin{aligned}
& \dot{V}=\sum_{J=1}^{M}\left[S_{j}\left(\Delta f_{\mathrm{j}}-\theta^{T} \zeta\left(S_{j}\right)\right]-S^{T} \lambda S+\right. \\
& \sum_{J=1}^{M} \frac{1}{\gamma_{s j}} \phi^{T} \cdot \dot{\phi}_{j}
\end{aligned}
$$

Based on $\boldsymbol{\phi}=\boldsymbol{\theta}^{*}-\boldsymbol{\theta} \rightarrow \boldsymbol{\theta}=\boldsymbol{\theta}^{*}-\boldsymbol{\phi}$

$$
\begin{aligned}
& \dot{\mathrm{V}}= \\
& \sum_{\mathrm{J}=1}^{\mathrm{M}}\left[\mathrm{S}_{\mathrm{j}}\left(\Delta \mathrm{f}_{\mathrm{j}}-\theta^{* \mathrm{~T}} \zeta\left(\mathrm{S}_{\mathrm{j}}\right)+\square^{\mathrm{T}} \zeta\left(\mathrm{S}_{\mathrm{j}}\right)\right]-\mathrm{S}^{\mathrm{T}} \lambda \mathrm{S}+\right. \\
& \sum_{\mathrm{J}=1}^{\mathrm{M}} \frac{1}{\gamma_{\mathrm{sj}}} \square^{\mathrm{T}} \cdot \dot{\square}_{\mathrm{j}}
\end{aligned}
$$

$$
\begin{aligned}
\dot{V}=\sum_{J=1}^{M}\left[S _ { j } \left(\Delta f_{\mathrm{j}}\right.\right. & \left.-\left(\theta^{*}\right)^{T} \zeta\left(S_{j}\right)\right]-S^{T} \lambda S \\
& \left.+\sum_{J=1}^{M} \frac{1}{\gamma_{s j}} \phi_{j}^{T}\left[\gamma_{s j} . S_{j} \cdot \zeta_{j}\left(S_{j}\right)+\dot{\phi}_{j}\right]\right)
\end{aligned}
$$


where $\dot{\boldsymbol{\theta}}_{\boldsymbol{j}}=\boldsymbol{\gamma}_{\boldsymbol{s j}} \boldsymbol{S}_{\boldsymbol{j}} \boldsymbol{\zeta}_{j}\left(\boldsymbol{S}_{\boldsymbol{j}}\right)$ is adaption law, $\dot{\phi}_{\boldsymbol{J}}=-\dot{\boldsymbol{\theta}}_{\boldsymbol{j}}=$ $-\gamma_{s j} S_{j} \zeta_{j}\left(S_{j}\right) \dot{V}$ is considered by

$$
\dot{V}=\sum_{j=1}^{m}\left[S_{j} \Delta f_{j}-\left(\left(\theta_{j}^{*}\right)^{T} \zeta_{j}\left(S_{j}\right)\right)\right]-S^{T} \lambda S
$$

The minimum error is defined by

$$
e_{m j}=\Delta f_{j}-\left(\left(\theta_{j}^{*}\right)^{T} \zeta_{j}\left(S_{j}\right)\right)
$$

Therefore $\dot{\boldsymbol{V}}$ is computed as

$$
\begin{aligned}
\dot{V} & =\sum_{j=1}^{m}\left[S_{j} e_{m j}\right]-S^{T} \lambda S \\
\leq & \sum_{j=1}^{m}\left|S_{j}\right|\left|e_{m j}\right|-S^{T} \lambda S \\
& =\sum_{j=1}^{m}\left|S_{j}\right|\left|e_{m j}\right|-\lambda_{j} S_{j}^{2} \\
& =\sum_{j=1}^{m}\left|S_{j}\right|\left(\left|e_{m j}\right|-\lambda_{j} S_{j}\right)
\end{aligned}
$$

For continuous function $g(x)$, and suppose $\varepsilon>0$ it is defined the fuzzy logic system in form of

$$
\operatorname{Sup}_{x \in U}|f(x)-g(x)|<\epsilon
$$

the minimum approximation error $\left(e_{m j}\right)$ is very small.

$$
\begin{aligned}
& \text { if } \lambda_{j}=\alpha \text { that } \alpha\left|S_{j}\right|> \\
& e_{m j}\left(S_{j} \neq 0\right) \quad \text { then } \dot{V}<0 \text { for }\left(S_{j} \neq 0\right)
\end{aligned}
$$

This method has two main controller's coefficients, $K_{p}$ and $K_{V}$. To tune and optimize these parameters mathematical formulation is used

$$
\begin{aligned}
& U=\left(U_{\text {fuzzy }}+U_{\text {sliding }}\right) \times U_{P D} \\
& \left.\mathrm{U}=\mathrm{U}_{\text {fuzzy }}+\mathrm{U}_{\text {switch }}\right) \times U_{P D}= \\
& {\left[\boldsymbol{M}^{-\mathbf{1}}(\boldsymbol{B}+\boldsymbol{C}+\boldsymbol{G})+\dot{\boldsymbol{S}}\right] \boldsymbol{M}+\boldsymbol{K} \cdot \operatorname{sgn}(\boldsymbol{S})+} \\
& \frac{\sum_{\mathrm{l}=1}^{\mathrm{M}} \theta^{\mathrm{l}}\left[\prod_{\mathrm{i}=1}^{\mathrm{n}} \exp \left(-\left(\frac{\mathrm{x}_{\mathrm{i}}-\alpha_{\mathrm{i}}^{\mathrm{l}}}{\delta_{\mathrm{i}}^{\perp}}\right)^{2}\right)\right]}{\sum_{\mathrm{l}=1}^{\mathrm{M}}\left[\prod_{\mathrm{i}=1}^{\mathrm{n}} \exp \left(-\left(\frac{\mathrm{x}_{\mathrm{i}}-\alpha_{\mathrm{i}}^{\mathrm{l}}}{\delta_{\mathrm{i}}^{l}}\right)^{2}\right)\right]} \times\left(\boldsymbol{K}_{\boldsymbol{p}_{\boldsymbol{a}}} \boldsymbol{e}_{\mathbf{1}}+\right. \\
& \left.\boldsymbol{K}_{\boldsymbol{V}_{\boldsymbol{a}}} \dot{\boldsymbol{e}_{\mathbf{1}}}\right)
\end{aligned}
$$

The most important different between $\mathrm{PD} \times \mathrm{SMC}$ and $\mathrm{PD} \times \mathrm{SMC}+\mathrm{FL}$ is the uncertainty. In $\mathrm{PD} \times \mathrm{SMC}$ the uncertainty is $d=G+F+f$. The sliding mode gain must be bigger than its upper bound. It is not an easy job because this term includes tracking errors $e_{1}$ and $\dot{q}_{1}$. While in PD $\times$ SMC+FL, the uncertainty $\eta$ is the fuzzy approximation error for $G+F+f$.

$$
G+F+f=\frac{\sum_{l=1}^{M} \theta^{l}\left[\prod_{i=1}^{n} \exp \left(-\left(\frac{x_{i}-\alpha_{i}^{l}}{\delta_{i}^{l}}\right)^{2}\right)\right]}{\sum_{l=1}^{M}\left[\prod_{i=1}^{n} \exp \left(-\left(\frac{x_{i}-\alpha_{i}^{l}}{\delta_{i}^{l}}\right)^{2}\right)\right]}
$$

It is usually is smaller than $G+F+f$; and the upper bound of it is easy to be estimated. Figure 3 shows the PD controller with serial PD fuzzy variable structure controller.

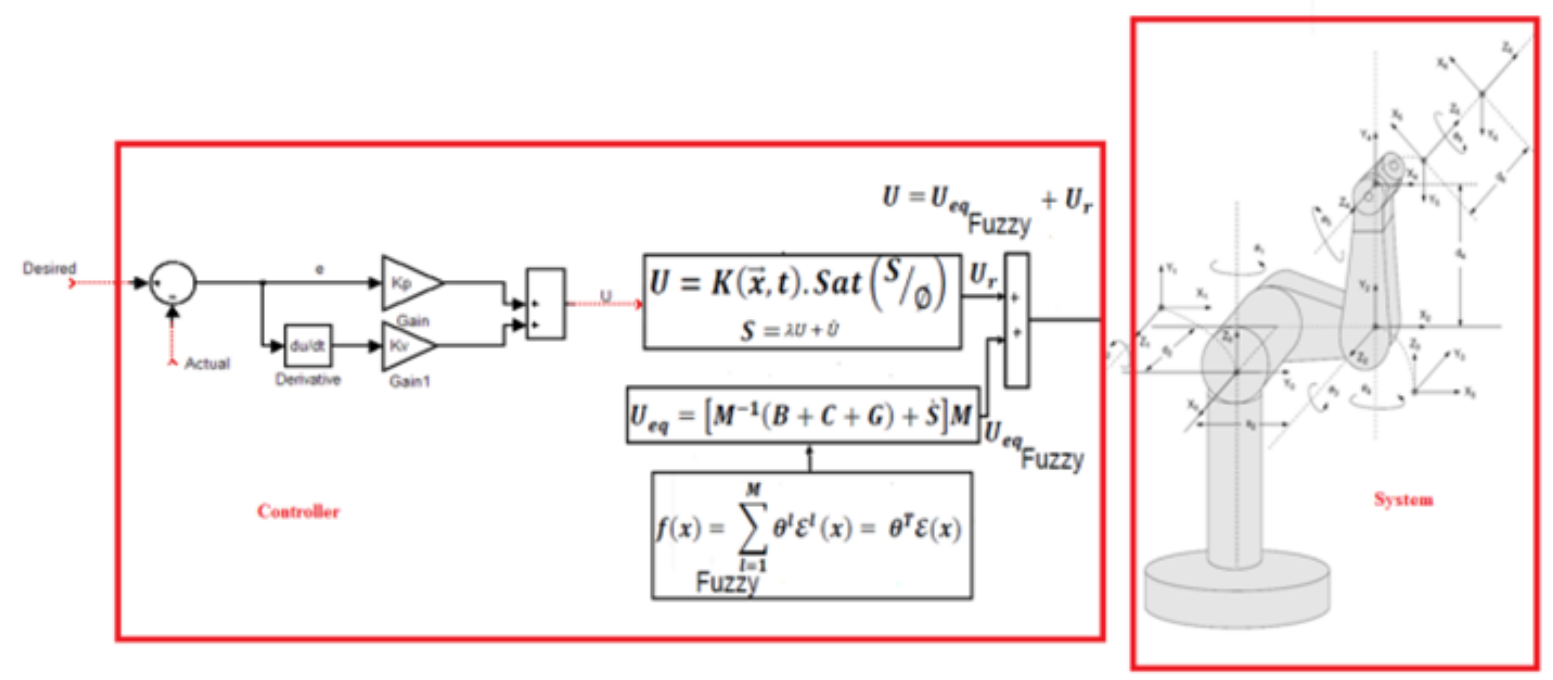

Fig. 3: PD with fuzzy VSC Compensator

\section{Results and Discussion}

Linear PD controller (PD) and proposed PD with SISO fuzzy variable structure estimator were tested to sinus response trajectory. The simulation was implemented in MATLAB/SIMULINK environment. Links trajectory and disturbance rejection are compared in these controllers. It is noted that, these systems are tested by band limited white noise with a predefined $40 \%$ of relative to the input signal amplitude. This type of 
noise is used to external disturbance in continuous and hybrid systems.

Trajectory: Figure 4 shows the links trajectory in PD controller and proposed PD with SISO fuzzy variable structure estimator without disturbance for sinus trajectory in general and zoom scaling because all 3 links have the same response so, all links are shown in a graph.

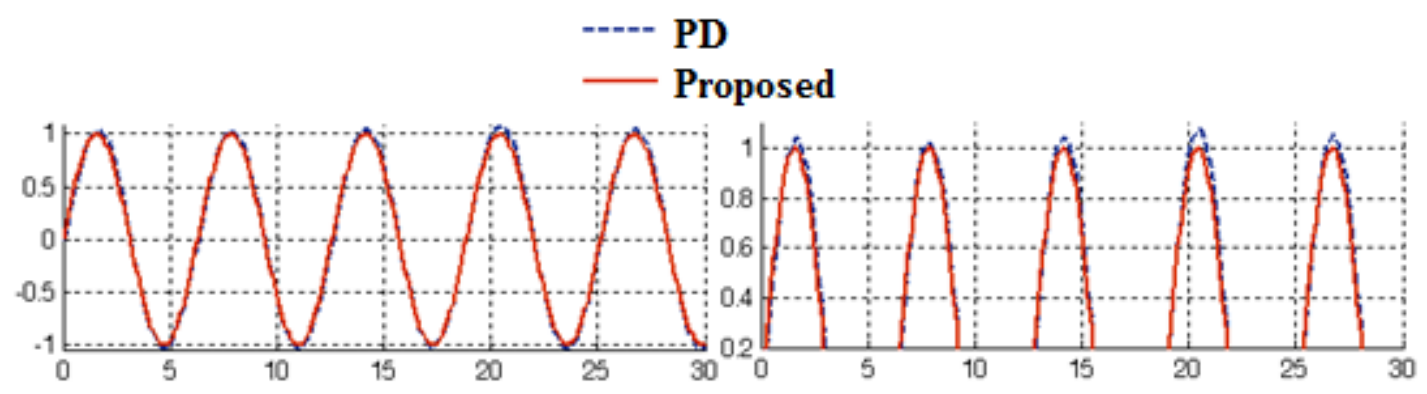

Fig. 4: PD Vs. Proposed method: Robot arm

By comparing sinus response, Figure 4, in PD controller and PD with SISO fuzzy variable structure estimator, we can seen the the proposed controller's overshoot (0\%) is lower than PD's (8\%).

Disturbance rejection: Figure 5 is indicated the power disturbance removal in PD controller and PD with SISO fuzzy variable structure estimation. Besides a band limited white noise with predefined of $40 \%$ the power of input signal is applied to the sinus PD controller and proposed method; it found slight oscillations in PD trajectory responses. All 3 links are shown in one graph.

\section{Proposed}
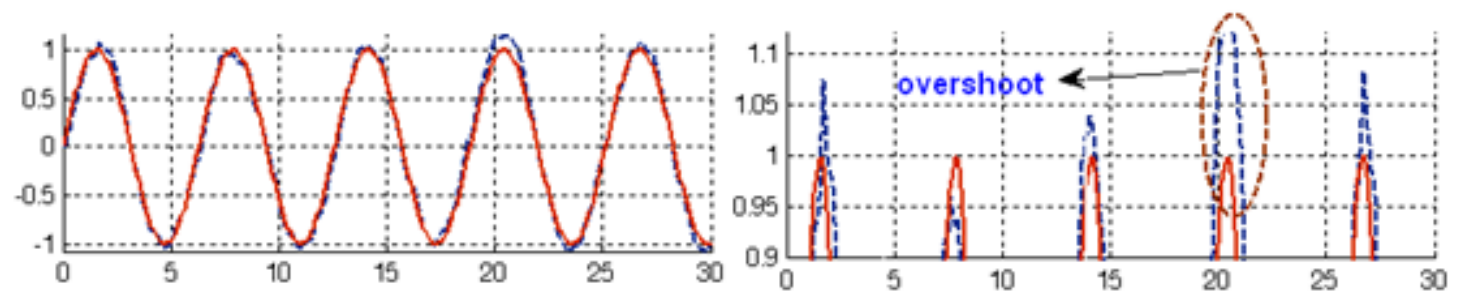

Fig. 5: PD Vs. Proposed method: Robot arm with external disturbance

Among above graph, relating to sinus trajectory following with external disturbance, PD controller has slightly fluctuations. By comparing overshoot; proposed controller's overshoot (0\%) is lower than PD's (22\%).

\section{Conclusion}

Refer to the research, a Lyapunov based SISO fuzzy variable structure estimator PD controller design and application to robot arm has proposed in order to design high performance nonlinear estimator in the presence of uncertainties and external disturbances. Regarding to the positive points in linear PD controller, variable structure controller and fuzzy inference system it is found that the fuzzy logic laws derived in the Lyapunov sense. The stability of the closed-loop system is proved mathematically based on the Lyapunov method. The first objective in proposed method is removed the chattering which artificial intelligence method is used to solve this challenge. The second target in this work is compensate the model uncertainty by SISO fuzzy inference system, in the case of robot arm, if we define $\boldsymbol{k}_{\mathbf{1}}$ membership functions for each input variable, the number of fuzzy rules applied for each joint is $\boldsymbol{K}_{\mathbf{1}}$ which will result in a low computational load. In finally part fuzzy variable structure methodology with minimum rule base is used to compensate and adjusted the PD controller. In this case the performance is improved by using the advantages of variable structure and artificial intelligence compensate while the disadvantages removed by added each method to previous method. 


\section{Acknowledgment}

The authors would like to thank the anonymous reviewers for their careful reading of this paper and for their helpful comments. This work was supported by the SSP Research and Development Corporation Program of Iran under grant no. 2012-Persian Gulf-1A.

\section{References}

[1] T. R. Kurfess, Robotics and automation handbook: CRC, 2005.

[2] J. J. E. Slotine and W. Li, Applied nonlinear control vol. 461: Prentice hall Englewood Cliffs, NJ, 1991.

[3] K. Ogata, Modern control engineering: Prentice Hall, 2009.

[4] J. J. D'Azzo, C. H. Houpis and S. N. Sheldon, Linear control system analysis and design with MATLAB: CRC, 2003.

[5] B. Siciliano and O. Khatib, Springer handbook of robotics: Springer-Verlag New York Inc, 2008.

[6] F. T. Cheng, T. L. Hour, Y. Y. Sun and T. H. Chen, "Study and resolution of singularities for a 6-DOF PUMA manipulator," Systems, Man, and Cybernetics, Part B: Cybernetics, IEEE Transactions on, No. 2, vol. 27, pp. 332-343, 2002.

[7] M. W. Spong and M. Vidyasagar, Robot dynamics and control: Wiley-India, 2009.

[8] Farzin Piltan, B. Boroomand, A. Jahed and H. Rezaie. "Performance-Based Adaptive Gradient Descent Optimal Coefficient Fuzzy Sliding Mode Methodology", International Journal of Intelligent Systems and Applications, 11: 40-52 2012.

[9] D. Nguyen-Tuong, M. Seeger and J. Peters, "Computed torque control with nonparametric regression models," IEEE conference proceeding, 2008, pp. 212-217.

[10] Farzin Piltan, N. Sulaiman, Zahra Tajpaykar, Payman Ferdosali, Mehdi Rashidi, "Design Artificial Nonlinear Robust Controller Based on CTLC and FSMC with Tunable Gain," International Journal of Robotic and Automation, 2 (3): 205-220, 2011.

[11] Farzin Piltan, A. R. Salehi and Nasri B Sulaiman.," Design artificial robust control of second order system based on adaptive fuzzy gain scheduling," world applied science journal (WASJ), 13 (5): 1085-1092, 2011.

[12] Farzin Piltan, N. Sulaiman, Atefeh Gavahian, Samira Soltani, Samaneh Roosta, "Design Mathematical Tunable Gain PID-Like Sliding Mode Fuzzy Controller with Minimum Rule Base,"
International Journal of Robotic and Automation, 2 (3): 146-156, 2011.

[13] Farzin Piltan , A. Zare, Nasri B. Sulaiman, M. H. Marhaban and R. Ramli, , "A Model Free Robust Sliding Surface Slope Adjustment in Sliding Mode Control for Robot Manipulator," World Applied Science Journal, 12 (12): 2330-2336, 2011.

[14] Farzin Piltan , A. H. Aryanfar, Nasri B. Sulaiman, M. H. Marhaban and R. Ramli "Design Adaptive Fuzzy Robust Controllers for Robot Manipulator," World Applied Science Journal, 12 (12): $2317-$ 2329, 2011.

[15] Farzin Piltan, N. Sulaiman , Arash Zargari, Mohammad Keshavarz, Ali Badri, "Design PIDLike Fuzzy Controller With Minimum Rule Base and Mathematical Proposed On-line Tunable Gain: Applied to Robot Manipulator," International Journal of Artificial intelligence and expert system, 2 (4):184-195, 2011.

[16] Farzin Piltan, Nasri Sulaiman, M. H. Marhaban and R. Ramli, "Design On-Line Tunable Gain Artificial Nonlinear Controller," Journal of Advances In Computer Research, 2 (4): 75-83, 2011.

[17] Farzin Piltan, N. Sulaiman, Payman Ferdosali, Iraj Assadi Talooki, "Design Model Free Fuzzy Sliding Mode Control: Applied to Internal Combustion Engine," International Journal of Engineering, 5 (4):302-312, 2011.

[18] Farzin Piltan, N. Sulaiman, Samaneh Roosta, M.H. Marhaban, R. Ramli, "Design a New Sliding Mode Adaptive Hybrid Fuzzy Controller," Journal of Advanced Science \& Engineering Research , 1 (1): 115-123, 2011.

[19] Farzin Piltan, Atefe Gavahian, N. Sulaiman, M.H. Marhaban, R. Ramli, "Novel Sliding Mode Controller for robot manipulator using FPGA," Journal of Advanced Science \& Engineering Research, 1 (1): 1-22, 2011.

[20] Farzin Piltan, N. Sulaiman, A. Jalali \& F. Danesh Narouei, "Design of Model Free Adaptive Fuzzy Computed Torque Controller: Applied to Nonlinear Second Order System," International Journal of Robotics and Automation, 2 (4):232-244, 2011.

[21] Farzin Piltan, N. Sulaiman, Iraj Asadi Talooki, Payman Ferdosali, "Control of IC Engine: Design a Novel MIMO Fuzzy Backstepping Adaptive Based Fuzzy Estimator Variable Structure Control ," International Journal of Robotics and Automation, 2 (5):360-380, 2011.

[22] Farzin Piltan, N. Sulaiman, Payman Ferdosali, Mehdi Rashidi, Zahra Tajpeikar, “Adaptive MIMO Fuzzy Compensate Fuzzy Sliding Mode Algorithm: Applied to Second Order Nonlinear System," 
International Journal of Engineering, 5 (5): 380398, 2011.

[23] Farzin Piltan, N. Sulaiman, Hajar Nasiri, Sadeq Allahdadi, Mohammad A. Bairami, "Novel Robot Manipulator Adaptive Artificial Control: Design a Novel SISO Adaptive Fuzzy Sliding Algorithm Inverse Dynamic Like Method," International Journal of Engineering, 5 (5): 399-418, 2011.

[24] Samira Soltani \& Farzin Piltan, "Design Artificial Nonlinear Controller Based on Computed Torque like Controller with Tunable Gain". World Applied Science Journal,14 (9): 1306-1312, 2011.

[25] Farzin Piltan, N. Sulaiman, Sadeq Allahdadi, Mohammadali Dialame, Abbas Zare, "Position Control of Robot Manipulator: Design a Novel SISO Adaptive Sliding Mode Fuzzy PD Fuzzy Sliding Mode Control," International Journal of Artificial intelligence and Expert System, 2 (5):208-228, 2011.

[26] Farzin Piltan, SH. Tayebi HAGHIGHI, N. Sulaiman, Iman Nazari, Sobhan Siamak, "Artificial Control of PUMA Robot Manipulator: A-Review of Fuzzy Inference Engine And Application to Classical Controller ," International Journal of Robotics and Automation, 2 (5):401-425, 2011.

[27] Farzin Piltan, N. Sulaiman, Abbas Zare, Sadeq Allahdadi, Mohammadali Dialame, "Design Adaptive Fuzzy Inference Sliding Mode Algorithm: Applied to Robot Arm," International Journal of Robotics and Automation , 2 (5): 283-297, 2011.

[28] Farzin Piltan, Amin Jalali, N. Sulaiman, Atefeh Gavahian, Sobhan Siamak, "Novel Artificial Control of Nonlinear Uncertain System: Design a Novel Modified PSO SISO Lyapunov Based Fuzzy Sliding Mode Algorithm ," International Journal of Robotics and Automation, 2 (5): 298316, 2011.

[29] Farzin Piltan, N. Sulaiman, Amin Jalali, Koorosh Aslansefat, "Evolutionary Design of Mathematical tunable FPGA Based MIMO Fuzzy Estimator Sliding Mode Based Lyapunov Algorithm: Applied to Robot Manipulator," International Journal of Robotics and Automation, 2 (5):317-343, 2011.

[30] Farzin Piltan, N. Sulaiman, Samaneh Roosta, Atefeh Gavahian, Samira Soltani, "Evolutionary Design of Backstepping Artificial Sliding Mode Based Position Algorithm: Applied to Robot Manipulator," International Journal of Engineering, 5 (5):419-434, 2011.

[31] Farzin Piltan, N. Sulaiman, S.Soltani, M. H. Marhaban \& R. Ramli, "An Adaptive sliding surface slope adjustment in PD Sliding Mode Fuzzy Control for Robot Manipulator,"
International Journal of Control and Automation , 4 (3): 65-76, 2011.

[32] Farzin Piltan, N. Sulaiman, Mehdi Rashidi, Zahra Tajpaikar, Payman Ferdosali, "Design and Implementation of Sliding Mode Algorithm: Applied to Robot Manipulator-A Review ," International Journal of Robotics and Automation, 2 (5):265-282, 2011.

[33] Farzin Piltan, N. Sulaiman, Amin Jalali, Sobhan Siamak, and Iman Nazari, "Control of Robot Manipulator: Design a Novel Tuning MIMO Fuzzy Backstepping Adaptive Based Fuzzy Estimator Variable Structure Control ," International Journal of Control and Automation, 4 (4):91-110, 2011.

[34] Farzin Piltan, N. Sulaiman, Atefeh Gavahian, Samaneh Roosta, Samira Soltani, "On line Tuning Premise and Consequence FIS: Design Fuzzy Adaptive Fuzzy Sliding Mode Controller Based on Lyaponuv Theory," International Journal of Robotics and Automation, 2 (5):381-400, 2011.

[35] Farzin Piltan, N. Sulaiman, Samaneh Roosta, Atefeh Gavahian, Samira Soltani, "Artificial Chattering Free on-line Fuzzy Sliding Mode Algorithm for Uncertain System: Applied in Robot Manipulator," International Journal of Engineering, 5 (5):360-379, 2011.

[36] Farzin Piltan, N. Sulaiman and I.AsadiTalooki, "Evolutionary Design on-line Sliding Fuzzy Gain Scheduling Sliding Mode Algorithm: Applied to Internal Combustion Engine," International Journal of Engineering Science and Technology, 3 (10):7301-7308, 2011.

[37] Farzin Piltan, Nasri B Sulaiman, Iraj Asadi Talooki and Payman Ferdosali.," Designing On-Line Tunable Gain Fuzzy Sliding Mode Controller Using Sliding Mode Fuzzy Algorithm: Applied to Internal Combustion Engine," world applied science journal (WASJ), 15 (3): 422-428, 2011.

[38] B. K. Yoo and W. C. Ham, "Adaptive control of robot manipulator using fuzzy compensator," Fuzzy Systems, IEEE Transactions on, No. 2, vol. 8, pp. 186-199, 2002.

[39] Y. S. Kung, C. S. Chen and G. S. Shu, "Design and Implementation of a Servo System for Robotic Manipulator," CACS, 2005.

[40] Farzin Piltan, N. Sulaiman, M. H. Marhaban, Adel Nowzary, Mostafa Tohidian," "Design of FPGA based sliding mode controller for robot manipulator," International Journal of Robotic and Automation, 2 (3): 183-204, 2011.

[41] Farzin Piltan, M. Mirzaie, F. Shahriyari, Iman Nazari \& S. Emamzadeh." Design Baseline Computed Torque Controller" International Journal of Engineering, 3(3): 2012. 
[42] Farzin Piltan, H. Rezaie, B. Boroomand, Arman Jahed," Design robust back stepping online tuning feedback linearization control applied to IC engine," International Journal of Advance Science and Technology, 42: 183-204, 2012.

[43] Farzin Piltan, I. Nazari, S. Siamak, P. Ferdosali,"Methodology of FPGA-based mathematical error-based tuning sliding mode controller" International Journal of Control and Automation, 5(1): 89-110, 2012.

[44] Farzin Piltan, M. A. Dialame, A. Zare, A. Badri ,'Design Novel Lookup table changed Auto Tuning FSMC: Applied to Robot Manipulator" International Journal of Engineering, 6(1): 25-40, 2012.

[45] Farzin Piltan, B. Boroomand, A. Jahed, H. Rezaie ,"Methodology of Mathematical ErrorBased Tuning Sliding Mode Controller" International Journal of Engineering, 6(2): 96-112, 2012.

[46] Farzin Piltan, F. Aghayari, M. R. Rashidian, M. Shamsodini,"A New Estimate Sliding Mode Fuzzy Controller for Robotic Manipulator" International Journal of Robotics and Automation, 3(1): 45-58, 2012.

[47] Farzin Piltan, M. Keshavarz, A. Badri, A. Zargari, "Design novel nonlinear controller applied to robot manipulator: design new feedback linearization fuzzy controller with minimum rule base tuning method" International Journal of Robotics and Automation, 3(1): 1-18, 2012.

[48] Farzin Piltan, A. Jahed, H. Rezaie and B. Boroomand." Methodology of Robust Linear Online High Speed Tuning for Stable Sliding Mode Controller: Applied to Nonlinear System", International Journal of Control and Automation, 5(3): 217-236, 2012.

[49] Farzin Piltan, A. Hosainpour, E. Mazlomian, M.Shamsodini, M.H Yarmahmoudi. "Online Tuning Chattering Free Sliding Mode Fuzzy Control Design: Lyapunov Approach" International Journal of Robotics and Automation, 3(3): 2012.

[50] Farzin Piltan, M.H. Yarmahmoudi, M. Shamsodini, E.Mazlomian, A.Hosainpour." PUMA-560 Robot Manipulator Position Computed Torque Control Methods Using MATLAB/SIMULINK and Their Integration into Graduate Nonlinear Control and MATLAB Courses" International Journal of Robotics and Automation, 3(3): 2012.

[51] Farzin Piltan, R. Bayat, F. Aghayari, B. Boroomand. "Design Error-Based Linear ModelFree Evaluation Performance Computed Torque Controller" International Journal of Robotics and Automation, 3(3): 2012.
[52] Farzin Piltan, S. Emamzadeh, Z. Hivand, F. Shahriyari \& Mina Mirazaei ." PUMA-560 Robot Manipulator Position Sliding Mode Control Methods Using MATLAB/SIMULINK and Their Integration into Graduate/Undergraduate Nonlinear Control, Robotics and MATLAB Courses" International Journal of Robotics and Automation, 3(3): 2012.

[53] Farzin Piltan, J. Meigolinedjad, S. Mehrara, S. Rahmdel. " Evaluation Performance of $2^{\text {nd }}$ Order Nonlinear System: Baseline Control Tunable Gain Sliding Mode Methodology" International Journal of Robotics and Automation, 3(3): 2012.

\section{Authors' Profiles}

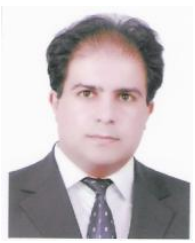

Farzin Piltan was born on 1975, Shiraz, Iran. In 2004 he is jointed the research and development company, SSP Co, Shiraz, Iran. In addition to 7 textbooks, Farzin Piltan is the main author of more than 64 scientific papers in refereed journals. $\mathrm{He}$ is editorial board of international journal of control and automation (IJCA), editorial board of IAES international journal of robotics and automation, editorial board of International Journal of Reconfigurable and Embedded Systems and reviewer of (CSC) international journal of robotics and automation. His main areas of research interests are nonlinear control, artificial control system and applied to FPGA, robotics and artificial nonlinear control and IC engine modeling and control.

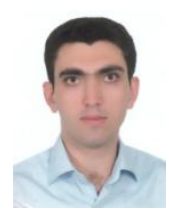

Saleh Mehrara is an electrical and electronic researcher of research and development company SSP. Co. His main areas are nonlinear control, artificial control system and robotics.

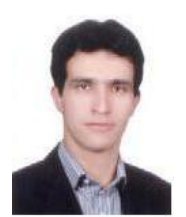

Javad Meigolinedjad is a mechanical engineer researcher of research and development company SSP. Co. He is now pursuing his Master in economic. $\mathrm{He}$ is an expert mechanical engineer in this company. His research activities deal with the robotics and artificial nonlinear control.

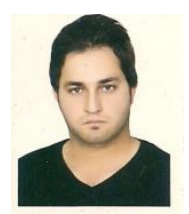

Reza Bayat is an electrical electronic researcher of research and development company SSP. Co. His main areas of research interests are nonlinear control, artificial control system and robotics. 